\title{
Landscape-Scale Implications of the Edge Effect on Soil Fauna Activity in a Temperate Forest
}

\author{
Terhi Riutta, ${ }^{1 *}$ Henry Clack, ${ }^{2}$ Martha Crockatt, ${ }^{3}$ and Eleanor M. Slade ${ }^{2,4}$
}

${ }^{1}$ Environmental Change Institute, School of Geography and the Environment, University of Oxford, South Parks Road, Oxford OX1 $3 Q Y$, UK; ${ }^{2}$ Wildlife Conservation Research Unit, Department of Zoology, University of Oxford, The Recanati-Kaplan Centre, Tubney House, Abingdon Road, Tubney, Abingdon OX13 5QL, UK; ${ }^{3}$ Earthwatch Institute, 256 Banbury Road, Oxford OX2 7DE, UK; ${ }^{4}$ Spatial Foodweb Ecology Group, Department of Applied Biology, University of Helsinki, PO Box 27, Latokartanonkaari 5, o0014 Helsinki, Finland

\begin{abstract}
Although studies on edge effects on species richness and abundance are numerous, the responses of ecosystem processes to these effects have received considerably less attention. How ecosystem processes respond to edge effects is particularly important in temperate forests, where small fragments and edge habitats form a considerable proportion of the total forest area. Soil fauna are key contributors to decomposition and soil biogeochemical cycling processes. Using the bait lamina technique, we quantified soil fauna feeding activity, and its dependence on soil moisture and distance to the edge in a broad-leaved forest in Southern England. Feeding activity was $40 \%$ lower at the forest edge than in the interior, and the depth of edge influence was approximately $75 \mathrm{~m}$. A watering treatment showed that moisture limitation was the main driver of the reduced feeding activity at the edge. In England, only 33\% of the
\end{abstract}

forest area is greater than $75 \mathrm{~m}$ from the edge. Therefore, assuming that the results from this single-site study are representative for the landscape, it implies that only one- third of the forest area in England supports activity levels typical for the forest core, and that edge effects reduce the mean feeding activity across the landscape by $17 \%$ (with lower and upper $90 \%$ confidence intervals of 1.3 and $23 \%$, respectively). Changing climatic conditions, such as summer droughts may exacerbate such effects as edges lose water faster than the forest interior. The results highlight the importance of taking edge effects into account in ecological studies and forest management planning in highly fragmented landscapes.

Key words: bait lamina; biodiversity-ecosystem functioning; climate change; fragmentation; macrofauna; upscaling.
Received 22 October 2014; accepted 14 May 2015; published online 29 December 2015

Electronic supplementary material: The online version of this article (doi:10.1007/s10021-015-9939-9) contains supplementary material, which is available to authorized users.

Author Contributions EMS, TR, HC and MC designed the study. HC performed the research. TR and EMS analysed the data. TR, EMS, MC and $\mathrm{HC}$ wrote the paper.

*Corresponding author; e-mail: terhi.riutta@ouce.ox.ac.uk

\section{INTRODUCTION}

Edge effects influence species' distributions and ecosystem processes. Forest edges are typically characterised by higher and more variable temperatures, higher vapour pressure deficits, and increased light and wind speeds compared with the forest core (Chen and others 1993; Young and Mitchell 1994; Chen and others 1995; Davies-Colley and others 2000). In particular, recent studies 
on the edge effect have indicated that increased evapotranspiration (mainly as a result of increased water use of trees) and reduced soil moisture levels near the forest edge are among the main drivers behind the differences in the ecosystem processes between the forest edge and core (Herbst and others 2007; Riutta and others 2012).

Such abiotic changes have typically been found to be most severe within $10-100 \mathrm{~m}$ from the edge (Laurance and others 2002; Ries and others 2004). However, the impacts of these changes are species and process specific as well as scale dependent, and there have been recent attempts to quantify the depth of edge influence (DEI) along a continuous gradient for individual processes (Ewers and Didham 2006a; Crockatt and Bebber 2014; Riutta and others 2014). Such studies suggest that fragments of less than nine hectares will be dominated by edge patterns and that fragments of less than one hectare will not support forest core conditions or vegetation associations (Young and Mitchell 1994; Riutta and others 2014).

Temperate forest is the most fragmented forest biome in the world (Wade and others 2003). In the UK, forest area has declined from around $75 \%$ of the land area 6000 years ago to less than $12 \%$ today (Watts 2006), and forest patch size distribution is highly skewed towards small patches; the mean patch size is 4.9 ha (Watts 2006). Assuming that a 4.9-ha patch is a perfect circle, 15,64 and $96 \%$ of the patch area would be within 10,50 and $100 \mathrm{~m}$ from the edge, respectively, with a maximum distance of $125 \mathrm{~m}$ from the edge. Considering all forest patches at least 2 ha in England, 13, 54 and $74 \%$ of the forest area lies within 10,50 and $100 \mathrm{~m}$ from the nearest edge, respectively (Riutta and others 2014). Thus, edge habitat is a predominant feature in the UK forests, and given the fragmented structure of the temperate biome, in other parts of the temperate forest zone as well, although such quantitative estimates are not available for other countries. Consequently, there is a need, not only to quantify the impact of edge effects and fragmentation on populations and ecosystem functioning, but also to develop models that allow us to assess the impact of the results at a landscape level (Ewers and others 2010; Cardinale and others 2012).

Many studies have focused on the direct abiotic changes at the edges of forest fragments (for example, Chen and others 1993; Didham and Lawton 1999; Davies-Colley and others 2000; Wuyts and others 2008), and the concurrent effects on the abundance and distribution of species (for example, Heske 1995; Ewers and Didham 2008;
Banks-Leite and others 2010), but far fewer have studied the indirect biological effects, such as changes in species interactions and ecosystem processes (for example, Didham 1998; Cadenasso and Pickett 2000; Riutta and others 2012; Moreno and others 2014). How ecosystem processes and functioning respond to edge effects is of importance to forest managers and conservationists studying both the effects of increasing forest fragmentation and ways to mitigate fragmentation effects through replanting. Moreover, the sensitivity of edge habitats to changes in climate (for example, increasing summer temperatures and decreasing summer precipitation (Jenkins and others 2009)) is of increasing importance.

In forest ecosystems, up to $75 \%$ of the total carbon stock is in the soil and litter (Ciais and others 2013), and the soil and litter layers contribute between 40 and $75 \%$ of the total forest ecosystem respiration (Goulden and others 1996; Yuste and others 2005; Saiz and others 2007). Soil fauna are key contributors to soil and litter respiration, they breakdown and recycle organic material, affect microbial activity, and are important ecosystem engineers (Seastedt 1984; Hassall and others 2006; Lavelle and others 2006; Osler and Sommerkorn 2007; Kampichler and Bruckner 2009). Temperature and moisture are the main drivers determining the activity and density of the soil fauna (Liiri and others 2002; Gongalsky and others 2008; Makkonen and others 2011), with reduced abundance and activity being found at the forest edges compared with the forest core (Haskell 2000; Simpson and others 2012).

In this study, we quantified the effect of the proximity to the forest edge and moisture availability on forest soil fauna feeding activity, using bait lamina sticks. Bait lamina sticks (Von Törne 1990) can be used as an indicator of the biological status of soils (van Gestel and others 2003; Römbke and others 2006; Gongalsky and others 2008) and are known to be palatable to soil macrofauna, mesofauna and microfauna (Helling and others 1998; van Gestel and others 2003; Römbke and others 2006). Specifically, we tested the following hypotheses: (i) soil fauna feeding activity decreases from the forest interior towards the forest edge, and (ii) soil fauna feeding activity is moisture limited and thus the low moisture level at the edge is the main driver of the hypothesised edge effect; therefore, adding water will increase the feeding activity, and reduce the edge effect. We then examined the potential implications of the results at the country level by extrapolating the observed patterns from the study site to broad-leaved and 
mixed forest patches across England, in typical conditions and under a simulated summer drought.

\section{Materials ANd Methods}

\section{Data Collection}

The study was carried out in Wytham Woods, a 400-ha semi-natural broad-leaved woodland in southern England $\left(51^{\circ} 46^{\prime} \mathrm{N}, 001^{\circ} 20^{\prime} \mathrm{W}\right)$. Mean annual temperature (1993-2009) in the study area is $10.1^{\circ} \mathrm{C}$ and average precipitation is $730 \mathrm{~mm}$ (UK Environmental Change Network monitoring program at Wytham; www.ecn.ac.uk). For further information on the site, see Butt and others (2009) and Savill and others (2010).

We set up six transects, three at the Northern and three at the Southern edge of the woodland, running from the forest edge to $100 \mathrm{~m}$ into the forest interior. The distance between the edges was approximately $2 \mathrm{~km}$ and the distance between the transects at each edge was approximately $60 \mathrm{~m}$. Ash (Fraxinus excelsior L.) and common oak (Quercus robur L.) were the dominant trees in the canopy, and hazel (Corylus avellana L.) and field maple (Acer campestre L.) in the shrub layer. The soil was a surface water gley of the Denchworth series in the England and Wales Soil Survey Classification (Clayden and Hollis 1984), and Stagni-vertic Cambisol in the FAO system. The forest was surrounded by agricultural land, and the boundary between the forest and the matrix was very sharp. On each transect, we set up a sampling station at 0 , 25, 50, 75 and 100 metres from the forest edge. Each sampling station had two plots of $50 \mathrm{~cm} \times 50 \mathrm{~cm}, 3 \mathrm{~m}$ apart. One of the plots was a control plot and in the other we applied a watering treatment. The watering treatment plots were watered every three days during the experiment, starting one day before the bait lamina sticks were placed into the soil. At each watering occasion, 1.25 litre of deionized water was added to the plot. This corresponded to a total of $30 \mathrm{ml}$ of extra rainfall during the 14-day bait lamina exposure period, which was equal to double the average rainfall in the site for the time of the year (rainfall data from the Wytham Woods weather station of the Environmental Change Network, Centre for Ecology and Hydrology, UK, 1993-2009). The impact of watering was assessed by measurement of volumetric soil moisture content in three spots in each plot every three days with a hand-held time delay reflectrometry (TDR) probe (HydroSense, Campbell Scientific Ltd., Shepshed, UK). Air temperature was recorded at three-hour intervals by data loggers
(Hygrochron ibutton; Embedded Data Systems, Lawrenceburg, KY, USA) placed at each sampling station, located at $1 \mathrm{~m}$ above the ground and protected by a weather shield.

Soil fauna feeding activity was measured using bait lamina sticks (Terra Protecta $\mathrm{GmbH}$, Berlin, Germany) of $200 \mathrm{~mm} \times 6 \mathrm{~mm} \times 1 \mathrm{~mm}$, made of PVC. The lower $10 \mathrm{~cm}$ of the stick had 16 biconical apertures of $1.5 \mathrm{~mm}$ in diameter, spaced $5 \mathrm{~mm}$ apart. These apertures were filled with bait made of powdered cellulose, bran flakes and activated carbon (70:27:3), mixed with distilled water. The paste was squeezed into the holes by hand and left to dry at room temperature. Each aperture was verified as being filled completely by holding the sticks against a light source after the bait had dried.

The sticks were inserted vertically into the soil, the uppermost hole at the leaf litter-soil surface interface and the bottommost hole at $7.5-\mathrm{cm}$ depth, and left in place for 14 days. The experiment was run twice: at the end of May and at the end of June. In May, a cluster of five sticks, and in June, a cluster of six, were placed in each plot in a $10 \mathrm{~cm} \times 10-\mathrm{cm}$ grid. After the retrieval, the number of perforated apertures was assessed visually in the laboratory by holding the sticks against light (binary variable, either perforated or not). In an earlier study on the same site, defaunated control mesocosms were used for testing the direct effect of microbes on the bait. No perforations were observed in the absence of soil fauna (Simpson and others 2012).

All analyses and results of this study are based on the visual assessment of the bait laminae, but to evaluate the method, each stick was also photographed against a constant light source, and the area of the perforations was analysed with Image J software (Schneider and others 2012) to allow a non-subjective methodological comparison. The results were consistent, and the conclusions of the study are thus the same regardless of the method used (see Appendix 1 in Supplementary material).

\section{Statistical Analyses}

The soil moisture, temperature and feeding activity data were analysed using linear mixed-effect models and general additive models, using the nlme (Pinheiro and others 2012) and gamm4 (Wood 2011) packages of the R software (R Core Team 2012).

\section{Soil Moisture}

The aim was to assess the effect of the watering treatment and distance to the edge on soil moisture levels. The dependent variable was the mean value 
of the three soil moisture readings per plot recorded every 3 days. Watering treatment and site (North or South) were included as fixed factors and distance from the edge as covariate. Transect, plot and month were included as nested random effects. In the full model, all interactions were included, and non-significant interactions dropped until the minimal adequate model was found. Temporal dependence of errors was modelled with a first-order autoregressive correlation structure (Zuur and others 2009). In the full model, all interactions were included and nonsignificant interactions dropped until the minimal adequate model was found.

\section{Temperature}

The dependent variable was the daily mean temperature. The fixed part of the model included Site (North or South), distance from the edge (covariate) and their interaction; and the random part had transect and plot as the nested random effects. Temporal dependence of errors was modelled with a first-order autoregressive correlation structure.

\section{Feeding Activity}

The binary variable of perforations derived from the visual assessment of the bait lamina sticks was used as a measure of feeding activity. Using a binomial model, the feeding activity was modelled with watering treatment and site (North or South) as fixed factors; distance from the edge as a covariate; and transect, plot and month as nested random effects. In the full model, all interactions were included and non-significant interactions dropped until the minimal adequate model was found. Feeding depth was included as a penalised spline smoother (Zuur and others 2009). We tested whether the feeding depth pattern differed between the control and watered plots and/or at different distances from the edge and/or between North and South by comparing an overall depth smoother with separate smoothers by treatments and distances. The models with different smoother structures were compared using AIC scores.

We used semi-variograms to examine the spatial autocorrelation of the residuals of the moisture, temperature and feeding activity models using $\mathrm{R}$ package geoR (Ribeiro and Diggle 2001; Diggle and Ribeiro 2007). No spatial autocorrelation patterns were detected.

\section{Upscaling to Country Level}

To illustrate the magnitude of the edge effect on soil processes in a wider forest landscape we extrapolated the results of this study for all broad- leaved and mixed forest patches in England. We used the map of forest patches at least 2 ha in England (Forestry Commission 2002), from which we extracted all broad-leaved and mixed forest patches. Using the approach by Riutta and others (2014), we calculated a continuous surface of the distance from within each forest patch to the nearest open edge (edges bordering other forest types, such as coniferous forests were not considered "true" forest edges) and a continuous surface of soil moisture as a function of distance from the edge. These maps were then combined with the model for feeding activity as a function of soil moisture, thus creating a continuous surface of soil fauna feeding activity across the forest landscape. We also recalculated the results based on a drought scenario where the summer moisture level was reduced by 20 percentage points. Based on the earlier study in the same forest (Simpson and others 2012), we assumed that feeding activity did not increase beyond $100 \mathrm{~m}$ from the edge. The GIS analyses were done in ArcGIS 10.0 and 10.1. As the upscaling was based on empirical results from a single study site, the upscaled estimates have to be treated with caution. To assess the robustness of the estimates, we carried out an uncertainty analysis, focussing on two sources of uncertainty: (i) variation in soil moisture gradient from core towards the edge across the landscape and (ii) variation in the response of the soil fauna feeding activity to moisture across the landscape. We generated 5000 alternative scenarios for soil moisture and soil fauna feeding activity, aiming to cover the whole range of ecologically plausible soil moisture conditions and feeding activity responses. We then repeated the upscaling for the landscape using each of these alternative scenarios. The uncertainty analysis is described in detail in Appendix 2.

\section{Results}

Soil moisture decreased from the forest interior towards the forest edge $\left(\mathrm{F}_{1,51}=17.7, P=0.0001\right.$; Figure 1A). The watered plots had higher soil moisture levels than the control plots $\left(F_{1,51}=6.91\right.$, $\mathrm{p}=0.0113)$, and the watering treatment effect decreased towards the forest edge (significant Distance $\times$ Watering treatment interaction; $\left.F_{1,51}=4.79, P=0.0332\right)$. Neither the moisture levels, nor the watering treatment effect, differed between the Northern and Southern edges ( $P$-values of the main effect and all interactions $>0.05$ ). Temperature did not vary along the distance from the edge or between the Northern and Southern 

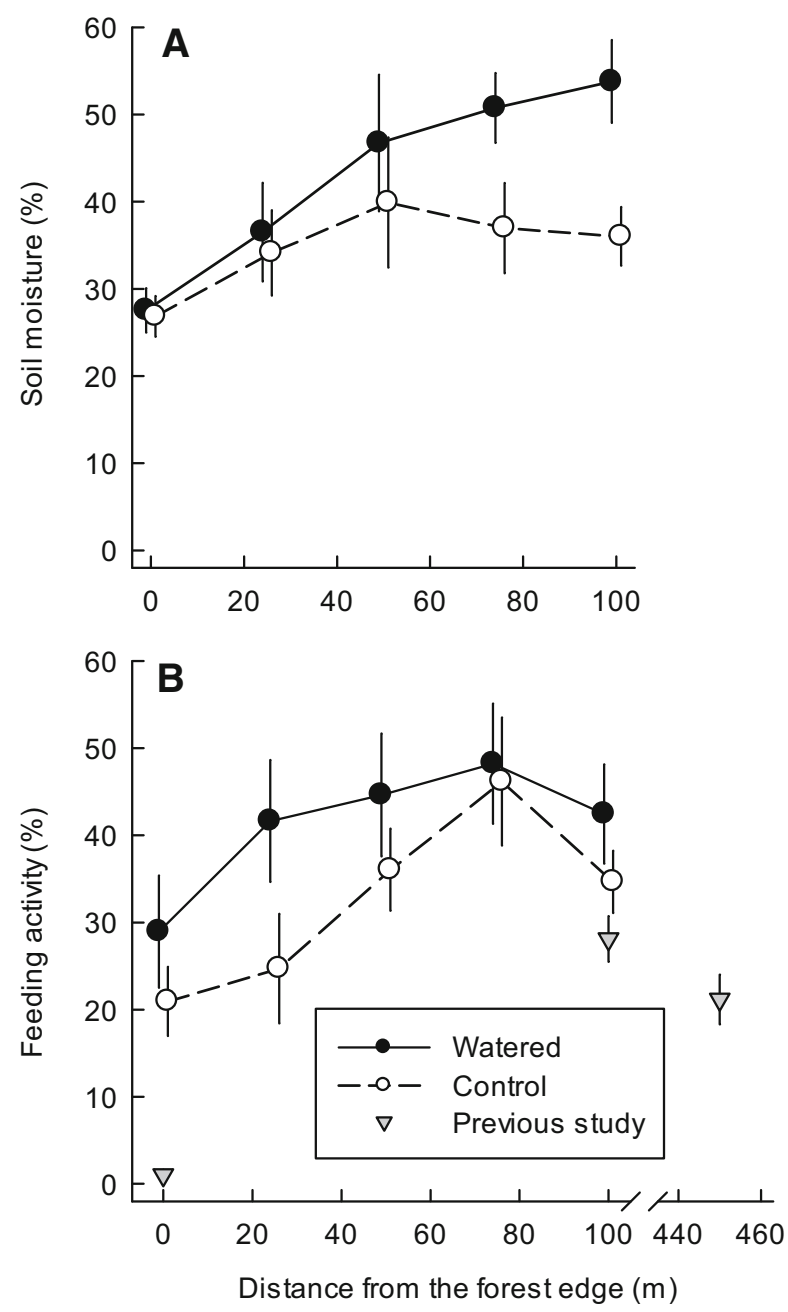

Figure 1. Variation (mean $\pm \mathrm{SE}$ ) of $\mathbf{A}$ soil moisture and B soil fauna feeding activity as a function of the distance from the nearest forest edge towards the forest core. In $\mathbf{B}$, data from the previous study (Simpson and others 2012) in the same site and using the same bait laminae are also shown to illustrate the feeding activity across a longer transect. The data points in different treatments are slightly offset in the $\mathrm{x}$-axis for visual clarity.

edges ( $P$ value of the main effects and the interaction $>0.5)$.

Soil fauna feeding activity decreased by $40 \%$ over the $100-\mathrm{m}$ distance from the forest interior towards the forest edge $\left(\chi_{1}^{2}=13.0, \quad P=0.0003\right.$; Figure 1B), which matches the pattern seen in an earlier study at the same site (Simpson and others 2012) (Figure 1B). Feeding activity was higher in the watered than in the control plots $\left(\chi_{1}^{2}=86.4\right.$, $P<0.0001)$. The watering treatment effect on the feeding activity was strongest at the edge (on average $38 \%$ increase compared with the control values) and decreased towards the forest interior (22\% increase compared with the control values) (significant Distance $\times$ Watering treatment interaction; $\left.\chi_{1}^{2}=17.1, P<0.0001\right)$. The feeding activity patterns did not differ between the Northern and Southern edges ( $P$ values of the main effect and all interactions $>0.05$ ).

Feeding activity was highest in the top soil and decreased exponentially with depth (Figure 2; $P$ values of the smoothers $<0.0001)$. The feeding depth pattern was different at the zero metre distance from the forest edge compared with the other sampling distances; at the very edge of the forest there was less feeding at the intermediate soil layers. Two smoothers for depth (one for the zero metre distance, one for the other distances) provided the optimal model structure (comparison based on AIC scores, difference between AIC values $\geq 5$ ). Other options tested were one universal smoother, separate smoothers for all distances, separate smoothers by watering treatment, separate smoothers for Northern and Southern edges, and different combinations of these groups.

The feeding activity was simulated for the whole forest landscape in England, by modelling the dependence of feeding activity on soil moisture and distance from the forest edge (Figure 3), and combining the response functions with the continuous maps for distance from the edge and soil moisture (Figure 4). Under typical moisture conditions, the mean modelled feeding activity across the fragmented landscape was $35 \%$ of bait lamina apertures perforated. Feeding activity showed saturation at around $75 \mathrm{~m}$ from the nearest edge (Figures 1B, 3B, 4C), and the mean feeding activity beyond that distance was $42 \%$ of apertures perforated. Thus, the edge effect reduced the feeding activity in the landscape by $17 \%$. The upper and lower $90 \%$ confidence intervals around the estimate are $1.3 \%$ and $23 \%$, respectively, due to the uncertainty in the variation in soil moisture, and variation in feeding activity and its response to the environmental conditions (Appendix 2). Assuming a drought that decreased soil moisture levels by 20 percentage points, uniformly across all distances from the edge (Figure 3a), the mean landscapescale feeding activity would then be $24 \%$ of apertures perforated ( $31 \%$ reduction). In drought conditions, the relative reduction in the feeding activity would be higher in the edges compared with the forest core areas (Figure 4d). 


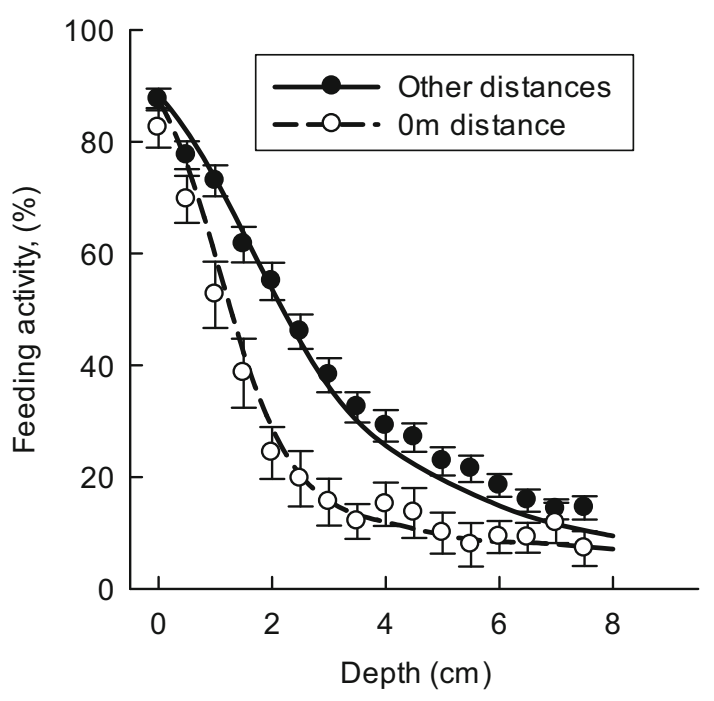

Figure 2. Vertical pattern in soil fauna feeding activity; $0 \mathrm{~cm}$ represents the leaf litter-soil surface interface. The points are mean feeding activities $( \pm S E)$ at each depth, and the lines are cubic regression smoothers derived from a general additive mixed effects model (see Methods for details). Model validation showed that the feeding depth pattern at the 0-m distance from the forest edge differed from the pattern at other distances.

\section{Discussion}

\section{Soil Fauna Feeding Activity and the Edge Effect}

We found a clear edge effect, with both soil moisture and soil fauna feeding activity increasing from the edge towards the forest core. Edge effects lessened between $50 \mathrm{~m}$ and $100 \mathrm{~m}$, suggesting that areas greater than $75 \mathrm{~m}$ from the forest edge will have similar soil fauna feeding activity to the forest core. Similarly, a previous study indicated that there was no difference in feeding activity between sites at $100 \mathrm{~m}$ and $450 \mathrm{~m}$ from the edge (Simpson and others 2012). The majority of feeding activity occurred within the first $2 \mathrm{~cm}$ of the soil surface. Feeding activity in the intermediate soil horizons (2-7-cm depth) was particularly reduced at the very edge of the forest; lower soil moisture so close to the edge may cause the soil to harden, and limit the vertical movement of the soil fauna (Eggleton and others 2009; Simpson and others 2012).

The watering treatment increased the feeding activity, and this was observed along the full length of the transects, indicating that feeding activity is moisture limited (see also Simpson and others 2012). The watering treatment increased the soil moisture levels more in the forest interior than at the edge, most likely because the added water was
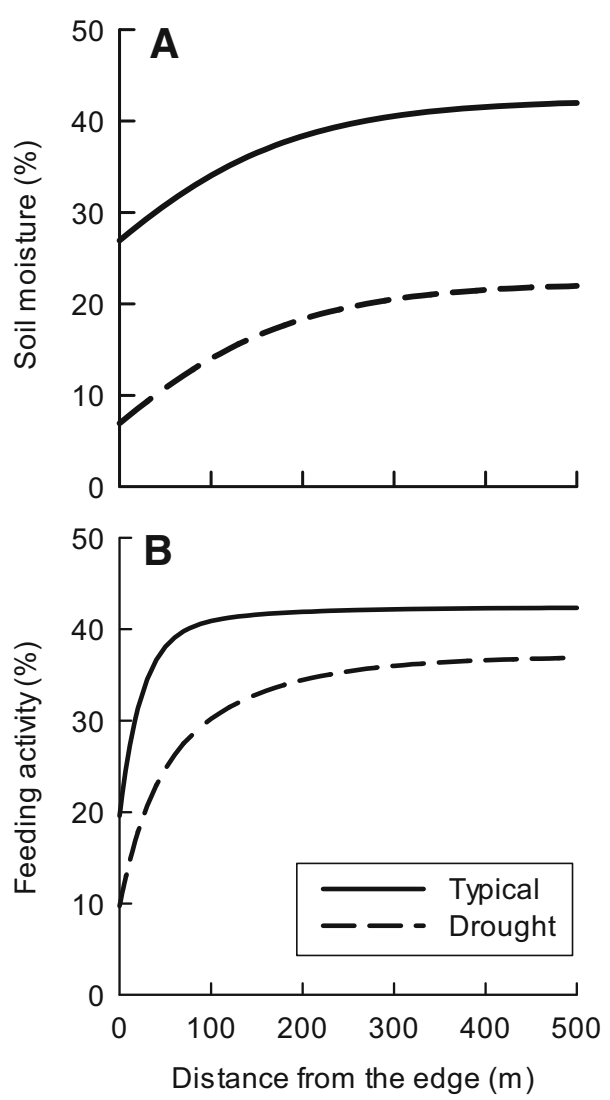

Figure 3. Modelled A soil moisture as a function of distance from the forest edge towards the forest core in typical conditions, and assuming a drought that lowers the soil moisture levels uniformly by 20 percentage points, and $\mathbf{B}$ soil fauna feeding activity, as a function of soil moisture and distance to the edge, taking into account that moisture co-varies with distance, as illustrated in $\mathbf{A}$.

lost faster near the edge due to the higher evapotranspiration rate (Didham and Lawton 1999; Herbst and others 2007). However, despite the smaller increases in the soil moisture levels, the increase in feeding activity due to the watering treatment was higher near the edge than in the interior, indicating higher moisture sensitivity near the edge, where the moisture limitation is at its most severe. Although soil fauna feeding activity has a positive response to temperature (Gongalsky and others 2008), and temperature has been shown to vary along the distance from the edge (Chen and others 1993, 1995; Davies-Colley and others 2000), in our study site, no temperature differences were observed (see also Riutta and others 2012; Simpson and others 2012). Therefore, the lower feeding activity at the forest edge compared with the forest interior was most likely driven by the changes in 



Figure 4. A Distance to the nearest open edge $(\mathrm{m})$ from within the forest patch in broad-leaved and mixed forests. B Soil moisture (\%) as a function of distance from the nearest open edge. C Soil fauna feeding activity (\%) in typical moisture conditions. D Decrease in soil fauna feeding activity (as \% change in the feeding activity in typical condition) during a simulated drought (20 percentage points decrease in soil moisture levels, compared with the feeding activity under typical moisture conditions). All analyses were done for the whole of England (grey insert), but for visual clarity, the results shown are an example from the white square in the insert. The map of forest patches is based on information supplied by the Forestry Commission 2002.

soil moisture. It is possible that the mechanism behind increased feeding activity with increases in soil moisture is driven partly by interactions with other trophic levels. For example, soil fauna may respond to the enhanced activity of microbes and primary producers.
In experimental microcosm-based studies, artificially assembled below-ground decomposer communities have been shown to be relatively insensitive to fragmentation (review by Rantalainen and others 2008). However, in these studies, only the fragment size and/or connectivity were 
allowed to vary, with no corresponding changes to the abiotic or biotic conditions. These studies suggest that with no associated changes in environmental conditions soil faunal communities are unaffected by the increase in habitat edge resulting from fragmentation. However, the effect of the fragmentation on the ecosystem processes may be indirect and mediated via an environmental factor. Our field study examined the contribution of soil fauna communities to ecosystem processes in natural conditions, showing a strong response to the proximity to the forest edge, which was mainly driven by lower moisture levels near the edge (see also Simpson and others 2012). The positive response to the watering treatment further supported the hypothesis that moisture availability was one of the main drivers of the soil fauna feeding activity. Therefore, making inferences about the effect of fragmentation based on experimental studies requires knowledge on both the variation of the environmental factors in the fragmented landscapes and the response of the community or process to those factors (Naeem 2008; Hillebrand and Matthiessen 2009; Peh and Lewis 2012).

\section{Soil Fauna Feeding Activity in a Fragmented Landscape}

To better understand and predict how biodiversity and ecosystem processes and services are affected by anthropogenic changes to the environment it is important to provide experimental links showing how changes in abiotic and biotic conditions affect ecosystem functioning. Developing models that allow us to scale these experimental results to whole landscapes is then an important next step if we are to inform policy and management initiatives (Cardinale and others 2012; Forsius and others 2013). The amount of forest area within varying distances from the forest edge has been recently quantified for England, producing spatially explicit data on fragmentation (Riutta and others 2014). Therefore, it is possible to combine the observed ecological responses with such fragmentation maps to examine the potential implications on a landscape scale, as suggested by Ewers and others (2010). Such spatially explicit models allow us to predict how forest edge effects might affect soil processes in a modelled landscape or under changing environmental conditions, where soil fauna feeding activity is a function of distance to the edge and soil moisture.

By upscaling our results to country level, we show the importance of considering the overall impact that edge effects can have on soil process rates, particularly in highly fragmented forests. Although we acknowledge that our model is a simplification, it provides a useful assessment-if not exact values-of the implications of the edge effect at the landscape scale. Although our data are from one study site only, and not necessarily quantitatively representative for the whole country, we used the results to illustrate, broadly, the general magnitude of the landscape-scale implications of the edge effect on soil fauna activity. As we are constrained by the lack of empirical data from multiple sites, we instead simulated the feeding activity under 5000 alternative scenarios, varying in moisture conditions and feeding activity levels, to illustrate the potential variation among forest patches. The analysis showed that the results are qualitatively robust: the edge effect resulted in reduction in feeding activity in $92 \%$ of the cases. However, taking into account the potential variation across the landscape may result into considerable variation in the edge effect, ranging from 1.3 to $23 \%$ reduction in feeding activity $(90 \%$ confidence intervals of the simulation results).

Feeding activity showed saturation around $75 \mathrm{~m}$ from the nearest edge (Figure 1B). Therefore, areas greater than $75 \mathrm{~m}$ from the nearest forest edge can be considered forest core in terms of soil fauna feeding activity. In England, only 33\% of the broad-leaved and mixed forest area is greater than $75 \mathrm{~m}$ from the nearest open edge (Riutta and others 2014). Thus, only one-third of the mixed and broad-leaved forest area could support soil fauna feeding activity levels typical for forest core areas. Moreover, edge effects may reduce the mean feeding activity by $17 \%$ across the English forest landscape (Figure 4), compared to a situation where the process is not influenced by the edge, or compared to a landscape where (unrealistically) there is no edge habitat.

The observed DEI on soil fauna feeding activity, approximately $75 \mathrm{~m}$, is intermediate, compared with some other ecological processes: tree growth about $6 \mathrm{~m}$ (Ewers and Didham 2006b), tree transpiration 20-30 m (Herbst and others 2007), occurrence of song birds 90-120 m (Fletcher 2005), abundance of forest specialist moths about $200 \mathrm{~m}$ (Slade and others 2013), and an extreme case, abundance of forest beetles greater than $1000 \mathrm{~m}$ (Ewers and Didham 2008). However, even in the case of this relatively short DEI, the country-level estimates for this process are considerably altered if the dependence of the feeding activity on the distance to the edge is taken into account, as opposed to just measuring feeding activity in the forest core area. This highlights the importance of taking edge 
effects into account in ecological studies, especially in regions where small patches form a considerable proportion of the total habitat area. It is worth noting that a randomly sampled point in a forest in England is almost three times as likely to be within $100 \mathrm{~m}$ from the edge than not, as $74 \%$ of the total forest area is within $100 \mathrm{~m}$ from the nearest open edge (Riutta and others 2014). Thus, even in cases where the edge effect or fragmentation is not part of the research question per se, researchers should select sampling designs that are representative of the landscape, rather than choosing "good sites" or "proper forest" within large patches, which are uncharacteristic of the fragmented landscapes we now live in. Although such quantitative estimates of edge-influenced forest area are not available for other countries, the pattern is probably similar in many other parts of the temperate zone, where only $4 \%$ of the broad-leaved and mixed forest area is located in an intact, unfragmented forest landscape (Potapov and others 2008).

Patches smaller than 2 ha comprise $75 \%$ of the total number of forest patches in the UK, although it amounts to only $6.8 \%$ of the total forest area (Watts 2006). With a DEI of $75 \mathrm{~m}$, the patches smaller than 2 ha have no core area at all; thus, $75 \%$ of the UK forest patches are effectively all edge with regards to soil fauna feeding activity. Forest cover in the UK is beginning to increase through replanting initiatives and buffering of remaining forest patches (Mason 2007). Our study allows us to assess the forest patch size needed to establish a forest core environment able to maintain a high level of soil fauna feeding activity. To achieve a core area of greater than $50 \%$ of the total area of the patch, the patch should be at least $21 \mathrm{ha}$, if the shape of the fragment is a circle. In practice, however, patches often have very irregular shapes, in which case considerably larger patches are needed to achieve a 50\% core area proportion.

\section{Soil Fauna Feeding Activity Under a Changing Climate}

In the UK, summer temperatures are predicted to increase and summer precipitation to decrease (Jenkins and others 2009). The largest impacts of climate change on the UK forests are predicted to be due to these summer droughts (Natural England and RSPB 2014). Forest edges have higher evapotranspiration rates than forest core areas (Herbst and others 2007), thus it is likely that edges will experience severer droughts than core areas. We modelled the drought effect by reducing the soil moisture levels by 20 percentage points, uniformly across all distances. This is a conservative approach, as droughts are likely to be severer at the edge than in the core. Even so, the modelled reduction in soil fauna feeding activity under the drought scenario was markedly higher at the edge $(50 \%$ lower than that under the typical moisture conditions) than in the core (13\% lower), as a result of the higher moisture sensitivity of the feeding activity near the edge. Although this modelling approach is a simplification and the effects of climate change will be complex and difficult to predict, there is already evidence that soil processes and fauna will be affected by changes in the global temperatures and in particular moisture (Aerts 2006). As these climatic variables also vary across the edge-core gradient, our results suggest that the configuration of the landscape is an essential factor to include in the models predicting the effects of climate change, especially in highly fragmented landscapes, such as temperate forests.

\section{Conclusions}

Although studies on edge effects on species richness and abundance are numerous, the responses of ecosystem processes to these effects have received considerably less attention. How soil processes are affected and influenced by proximity to the edge is particularly important in regions where forests are highly fragmented, such as in much of Europe, where a high proportion of the total forest area is edge influenced. The combined effects edge and moisture limitation on a key ecosystem process reflected at the landscape scale highlight the importance of taking edge effects into account in ecological studies and forest management planning in highly fragmented landscapes. Furthermore, changing climate conditions, such as warmer, drier summers, may exacerbate these effects with cascading consequences for soil ecosystems, through changes in decomposition, nutrient cycling, and hence plant growth and productivity. Therefore, forest management of existing temperate forests should aim to prevent further fragmentation of existing patches, and where possible, to create new, large areas of forest or to buffer forest edges through replanting.

\section{ACKNOWLEDGEMENTS}

We are grateful to Nigel Fisher and his team for the access to the study site and for their help with transporting water. Dan Bebber helped to design and set up the transects, and Phil Smith provided 
access to the facilities in the John Krebs Field Station. We thank Jake Simpson for sharing his expertise on bait lamina sticks. The study was funded by the HSBC Climate Partnership Programme through the Earthwatch Institute. EMS also acknowledges funding from the Academy of Finland: grant number 138346.

\section{OPEN ACCESS}

This article is distributed under the terms of the Creative Commons Attribution 4.0 International License (http://creativecommons.org/licenses/by/ 4.0/), which permits unrestricted use, distribution, and reproduction in any medium, provided you give appropriate credit to the original author(s) and the source, provide a link to the Creative Commons license, and indicate if changes were made.

\section{REFERENCES}

Aerts R. 2006. The freezer defrosting: global warming and litter decomposition rates in cold biomes. J Ecol 94:713-24.

Banks-Leite C, Ewers RM, Metzger J-P. 2010. Edge effects as the principal cause of area effects on birds in fragmented secondary forest. Oikos 119:918-26.

Butt N, Campbell G, Malhi Y, Morecroft M, Fenn K, Thomas M. 2009. Initial Results from Establishment of a Long-term Broadleaf Monitoring Plot at Wytham Woods, Oxford, UK. University of Oxford Report. Oxford: University of Oxford.

Cadenasso M, Pickett S. 2000. Linking forest edge structure to edge function: mediation of herbivore damage. J Ecol 88:3144.

Cardinale BJ, Duffy JE, Gonzalez A, Hooper DU, Perrings C, Venail P, Narwani A, Mace GM, Tilman D, Wardle DA, Kinzig AP, Daily GC, Loreau M, Grace JB, Larigauderie A, Srivastava DS, Naeem S. 2012. Biodiversity loss and its impact on humanity. Nature 486:59-67.

Chen JQ, Franklin JF, Spies TA. 1993. Contrasting microclimates among clear-cut, edge, and interior of old-growth douglas-fir forest. Agric For Meteorol 63:219-37.

Chen JQ, Franklin JF, Spies TA. 1995. Growing-season microclimatic gradients from clear-cut edges into old-growth douglas-fir forests. Ecol Appl 5:74-86.

Ciais P, Sabine C, Bala G, Bopp L, Brovkin V, Canadell J, Chhabra A, DeFries R, Galloway J, Heimann M, Jones C, Le Quere C, Myneni RB, Piao S, Thornton P. 2013. Carbon and Other Biochemical Cycles. Climate Change 2013: The Physical Science Basis. In: Stocker TF, Qin D, Plattner G-K, Tignor M, Allen SK, Boschung J, Nauels A, Xia Y, Bex V, Midgley PM, Eds. Contribution of Working Group I to the Fifth Assessment Report of the Intergovernmental Panel on Climate Change. Cambridge: Cambridge University Press.

Clayden B, Hollis JM. 1984. Criteria for differentiating soil series. Harpenden: Rothamsted Experimental Station.

Crockatt ME, Bebber DP. 2014. Edge effects on moisture reduce wood decomposition rate in a temperate forest. Global Change Biology. In Press.

Davies-Colley RJ, Payne GW, van Elswijk M. 2000. Microclimate gradients across a forest edge. N Zeal J Ecol 24:111-21.
Didham RK. 1998. Altered leaf-litter decomposition rates in tropical forest fragments. Oecologia 116:397-406.

Didham RK, Lawton JH. 1999. Edge structure determines the magnitude of changes in microclimate and vegetation structure in tropical forest fragments. Biotropica 31:17-30.

Diggle PJ, Ribeiro PJ. 2007. Model based geostatistics. New York: Springer.

Eggleton P, Inward K, Smith J, Jones DT, Sherlock E. 2009. A six year study of earthworm (Lumbricidae) populations in pasture woodland in southern England shows their responses to soil temperature and soil moisture. Soil Biol Biochem 41:1857-65.

Ewers RM, Didham RK. 2006a. Confounding factors in the detection of species responses to habitat fragmentation. Biol Rev 81:117-42.

Ewers RM, Didham RK. 2006b. Continuous response functions for quantifying the strength of edge effects. J Appl Ecol 43:527-36.

Ewers RM, Didham RK. 2008. Pervasive impact of large-scale edge effects on a beetle community. Proc Natl Acad Sci USA 105:5426-9.

Ewers RM, Marsh CJ, Wearn OR. 2010. Making statistics biologically relevant in fragmented landscapes. Trends Ecol Evol 25:699-704.

Fletcher RJ. 2005. Multiple edge effects and their implications in fragmented landscapes. J Anim Ecol 74:342-52.

Forestry Commission. 2002. National Inventory of Woodlands and Trees dataset (NIWT) Reference date 2002, (C) Crown copyright and database right [2002] Ordnance Survey [100021242]

Forsius M, Anttila S, Arvola L, Bergström I, Hakola H, Heikkinen H, Helenius J, Hyvärinen M, Jylhä K, Karjalainen J. 2013. Impacts and adaptation options of climate change on ecosystem services in Finland: a model based study. Curr Opin Environ Sustain 5(1):4-10.

Gongalsky KB, Persson T, Pokarzhevskii AD. 2008. Effects of soil temperature and moisture on the feeding activity of soil animals as determined by the bait-lamina test. Appl Soil Ecol 39:84-90.

Goulden ML, Munger JW, Fan SM, Daube BC, Wofsy SC. 1996. Exchange of carbon dioxide by a deciduous forest: response to interannual climate variability. Science 271:1576-8.

Haskell DG. 2000. Effects of forest roads on macroinvertebrate soil fauna of the Southern Appalachian mountains. Conserv Biol 14:57-63.

Hassall M, Adl S, Berg M, Griffiths B, Scheu S. 2006. Soil faunamicrobe interactions: towards a conceptual framework for research. Eur J Soil Biol 42:S54-60.

Helling B, Pfeiff G, Larink O. 1998. A comparison of feeding activity of collembolan and enchytraeid in laboratory studies using the bait-lamina test. Appl Soil Ecol 7:207-12.

Herbst M, Roberts JM, Rosier PTW, Taylor ME, Gowing DJ. 2007. Edge effects and forest water use: a field study in a mixed deciduous woodland. For Ecol Manag 250:176-86.

Heske EJ. 1995. Mammalian abundances on forest-farm edges versus forest interiors in southern Illinois: is there an edge effect? J Mammal 76:562-8.

Hillebrand H, Matthiessen B. 2009. Biodiversity in a complex world: consolidation and progress in functional biodiversity research. Ecol Lett 12:1405-19.

Jenkins GJ, Murphy JM, Sexton DS, Lowe JA, Jones P, Kilsby CG. 2009. UK Climate Projections: Briefing report. Exeter: Met Office Hadley Center. 
Kampichler C, Bruckner A. 2009. The role of microarthropods in terrestrial decomposition: a meta-analysis of 40 years of litterbag studies. Biol Rev 84:375-89.

Laurance WF, Lovejoy TE, Vasconcelos HL, Bruna EM, Didham RK, Stouffer PC, Gascon C, Bierregaard RO, Laurance SG, Sampaio E. 2002. Ecosystem decay of Amazonian forest fragments: a 22-year investigation. Conserv Biol 16:605-18.

Lavelle P, Decaëns T, Aubert M, Barot S, Blouin M, Bureau F, Margerie P, Mora P, Rossi JP. 2006. Soil invertebrates and ecosystem services. European Journal of Soil Biology 42(Suppl 1):S3-15.

Liiri M, Setälä H, Haimi J, Pennanen T, Fritze H. 2002. Soil processes are not influenced by the functional complexity of soil decomposer food webs under disturbance. Soil Biol Biochem 34:1009-20.

Makkonen M, Berg MP, van Hal JR, Callaghan TV, Press MC, Aerts R. 2011. Traits explain the responses of a sub-arctic Collembola community to climate manipulation. Soil Biol Biochem 43:377-84.

Mason W. 2007. Changes in the management of British forests between 1945 and 2000 and possible future trends. Ibis 149:41-52.

Moreno ML, Bernaschini ML, Pérez-Harguindeguy N, Valladares G. 2014. Area and edge effects on leaf-litter decomposition in a fragmented subtropical dry forest. Acta Oecol 60:26-9.

Naeem S. 2008. Advancing realism in biodiversity research. Trends Ecol Evol 23:414-16.

Natural England and RSPB. 2014. Climate Change Adaptation Manual.

Osler GH, Sommerkorn M. 2007. Toward a complete soil C and $\mathrm{N}$ cycle: incorporating the soil fauna. Ecology 88:1611-21.

Peh KS-H, Lewis SL. 2012. Conservation implications of recent advances in biodiversity-functioning research. Biol Conserv $151: 26-31$.

Pinheiro J, Bates D, DebRoy S. 2012. nlme: Linear and Nonlinear Mixed Effects Models. R package Version 3.1-104.

Potapov P, Yaroshenko A, Turubanova S, Dubinin M, Laestadius L, Thies C, Aksenov D, Egorov A, Yesipova Y, Glushkov I, Karpachevskiy M, Kostikova A, Manisha A, Tsybikova E, Zhuravleva I. 2008. Mapping the world's intact forest landscapes by remote sensing. Ecol Soc 13.

R Core Team. 2012. R: A language and environment for statistical computing. Vienna: R Foundation for Statistical Computing.

Rantalainen ML, Haimi J, Fritze H, Pennanen T, Setälä H. 2008. Soil decomposer community as a model system in studying the effects of habitat fragmentation and habitat corridors. Soil Biol Biochem 40:853-63.

Ribeiro PJ, Diggle PJ. 2001. geoR: a package for geostatistical analysis. R-NEWS 1:15-18.

Ries L, Fletcher RJ, Battin J, Sisk TD. 2004. Ecological responses to habitat edges: mechanisms, models, and variability explained. Annu Rev Ecol Evol Syst 35:491-522.

Riutta T, Slade EM, Bebber DP, Taylor ME, Malhi Y, Riordan P, Macdonald DW, Morecroft MD. 2012. Experimental evidence for the interacting effects of forest edge, moisture and soil macrofauna on leaf litter decomposition. Soil Biol Biochem 49:124-31

Riutta T, Slade EM, Morecroft MD, Bebber DP, Malhi Y. 2014. Living on the edge: quantifying the structure of a fragmented forest landscape in England. Landsc Ecol 1-13.

Römbke J, Höfer H, Garcia MV, Martius C. 2006. Feeding activities of soil organisms at four different forest sites in Central Amazonia using the bait lamina method. J Trop Ecol 22:313-20.

Saiz G, Black K, Reidy B, Lopez S, Farrell EP. 2007. Assessment of soil $\mathrm{CO} 2$ efflux and its components using a process-based model in a young temperate forest site. Geoderma 139:79-89.

Savill PS, Perrins CM, Kirby KJ, Fisher N, Eds. 2010. Wytham woods: Oxford's ecological laboratory. Oxford: Oxford University Press.

Schneider CA, Rasband WS, Eliceiri KW. 2012. NIH Image to ImageJ: 25 years of image analysis. Nat Meth 9:671-5.

Seastedt TR. 1984. The role of microarthropods in decomposition and mineralization processes. Annu Rev Entomol 29:25-46.

Simpson JE, Slade E, Riutta T, Taylor ME. 2012. Factors affecting soil fauna feeding activity in a fragmented lowland temperate deciduous woodland. PLOS ONE 7:e29616.

Slade EM, Merckx T, Riutta T, Bebber DP, Redhead D, Riordan P, Macdonald DW. 2013. Life-history traits and landscape characteristics predict macro-moth responses to forest fragmentation. Ecology 94(7):1519-30.

van Gestel CA, Kruidenier M, Berg MP. 2003. Suitability of wheat straw decomposition, cotton strip degradation and baitlamina feeding tests to determine soil invertebrate activity. Biol Fertil Soils 37:115-23.

Von Törne E. 1990. Assessing feeding activities of soil-living animals. I: Bait-lamina-tests. Pedobiologia 34:89-101.

Wade TG, Riitters KH, Wickham JD, Jones KB. 2003. Distribution and causes of global forest fragmentation. Conserv Ecol $7: 16$.

Watts K. 2006. British forest landscapes: the legacy of woodland fragmentation. Q J For 100:273-9.

Wood SN. 2011. Fast stable restricted maximum likelihood and marginal likelihood estimation of semiparametric generalized linear models. J R Stat Soc Ser B 73:3-36.

Wuyts K, De Schrijver A, Staelens J, Gielis L, Vandenbruwane J, Verheyen K. 2008. Comparison of forest edge effects on throughfall deposition in different forest types. Environ Pollut 156:854-61.

Young A, Mitchell N. 1994. Microclimate and vegetation edge effects in a fragmented podocarp-broadleaf forest in New Zealand. Biol Conserv 67:63-72.

Yuste JC, Nagy M, Janssens IA, Carrara A, Ceulemans R. 2005. Soil respiration in a mixed temperate forest and its contribution to total ecosystem respiration. Tree Physiol 25:609-19.

Zuur AF, Ieno EN, Walker N, Saveliev AA, Smith GM. 2009. Mixed effects models and extensions in ecology with R. New York: Springer. 